\title{
Teacher-related Challenges Affecting the Integration of Ethnomathematics Approaches into the Teaching of Geometry
}

\author{
Gladys Sunzuma ${ }^{1,2 *}$, Aneshkumar Maharaj ${ }^{2}$ \\ ${ }^{1}$ Bindura University of Science Education, Bindura, ZIMBABWE \\ ${ }^{2}$ University of Kwazulu Natal, Durban, SOUTH AFRICA
}

Received 17 August 2018 - Revised 1 March 2019 - Accepted 7 March 2019

\begin{abstract}
Geometry and culture are interrelated, making school geometry closely connected to the environment as well as culture in which it is taught. With regard to this connectedness, the Zimbabwean mathematics syllabus indicates that geometry should be connected to the learners' environment and culture. This article explores teacherrelated challenges to the integration of ethnomathematics approaches into the teaching of geometry. Findings are based on feedback received from questionnaires and focus-group discussions in which 40 in-service mathematics teachers expressed their views on the challenges that affect the integration of ethnomathematics approaches into the teaching of geometry. Major challenges included lack of knowledge on ethnomathematics approaches and how to integrate these approaches into the teaching of geometry; teachers' lack of geometry content knowledge, teachers' views of geometry taught in schools, teachers' competence in teaching geometry, teaching and professional experience as well as resistance to change by teachers. The study recommends that teacher training institutions need to redesign their curricula to include ethnomathematics approaches and that there is need for in-service training on ethnomathematics approaches.
\end{abstract}

Keywords: ethnomathematics approaches, geometry, culture, environment, social constructivism

\section{INTRODUCTION}

In Zimbabwe, mathematics is a compulsory subject in secondary schools because of its importance in the development of the country (Chiwiye, 2013). The Ordinary Level (henceforth 'O-Level') syllabus in mathematics comprises of a number of topics such as algebra, matrices, statistics, vectors and geometry (ZIMSEC, 2015). Geometry is one of the topics that contribute to the overall poor performance in mathematics (Jones, 2002). In Jones' (2002) view, studies in geometry help in developing the mind, and critical thinking. Further, it is useful for different applications in architecture and engineering. Geometry could be used to capture learners' interest, particularly learners who find other mathematics topics such as algebra to be challenging, because geometry is a rich source of visualization that can be used for the understanding of statistical, algebraic and other arithmetical concepts (Battista, 1999). Furthermore, geometry is useful in developing learners' spatial awareness and intuition, visualizations and in solving real-life problems (Sunzuma, Masocha \& Zezekwa, 2012). According to Jones (2002), if geometry is taught very well it improves learners' overall performance in mathematics.

Despite the importance of geometry, it remains a difficult topic for both teachers and learners due to lack of background knowledge, poor reasoning skill in geometry, geometric language, lack of visualizing abilities, teachers' instructional approaches and lack of instructional resources among others (Cangelosi, 1996; Mashingaidze, 2012; Noraini, 2006; Telima, 2011). Performance in geometry in Zimbabwe in general has been very poor. This is supported by evidence from ZIMSEC Examiners' Reports $(2009 ; 2010 ; 2011 ; 2015)$ which revealed that learners had several challenges when it comes to solving geometry problems. This gives the impression that

(C) 2019 by the authors; licensee Modestum Ltd., UK. This article is an open access article distributed under the terms and conditions of the Creative Commons Attribution License (http://creativecommons.org/licenses/by/4.0/). \gsunzuma@gmail.com (*Correspondence) $\square$ maharaja32@ukzn.ac.za 


\section{Contribution of this paper to the literature}

- This study concentrates on teacher-related challenges in the integration of ethnomathematics approaches into the teaching of geometry at a teacher-training institution. During their training, teachers should be exposed to teaching as well as learning environments with ethnomathematics approaches and training to integrate ethnomathematics approaches into geometry instruction. Teacher training should focus on developing teachers' geometrical content knowledge and pedagogical content knowledge in order for them to integrate ethnomathematics approaches effectively.

- Increasing the variety of studies on teacher-related challenges in integrating ethnomathematics approaches into the teaching of geometry can lead to improvement in the teaching of geometry and achievement in geometry in particular as well as mathematics in general. Having teachers with knowledge of ethnomathematics approaches and being able to use such approaches, might improve learners' ability in solving geometry problems, hence, would improve their achievement in geometry.

- Teacher-related factors are significant predictors of teachers' views towards the integration of ethnomathematics approaches into the teaching of geometry. This study provides a basis for further inquiry of how teachers' views and their knowledge of ethnomathematics approaches as well as how this impacts on their integration of ethnomathematics approaches into the classroom.

learners were not benefiting from the teaching approaches being used to teach geometry. Jones (2002) noted that the major problem is that there appears to be little appreciation of the learners' cultural backgrounds by teachers.

Researchers such as Bishop (2004), Matang and Owens (2004), and Matang (2009) observed that numerous researchers in mathematics education limited their concentration to the difficulties learners and teachers come across in learning school mathematics in the formal classroom setting. Abreu, Bishop and Presmeg (2002), Bishop (2004); and Matang and Owens (2004), however, put more emphasis on other factors outside the formal classroom that could improve learning in formal school mathematics. Jones (2002) argued that teaching geometry well consists of appreciating the history and cultural context of geometry as well as understanding its different uses in real-life situations. Learners' ethnomathematical knowledge can be used as a stepping stone to the teaching of geometry in the classroom. The incorporation of such knowledge into the teaching of geometry can be useful since the learners can link what they have experienced in their everyday lives to the geometry that they learn in the classroom.

The Zimbabwean mathematics syllabus emphasises that the teaching of geometry should be linked to the environment and its cultural aspects (ZIMSEC, 2015), and this forms the basis of ethnomathematics approaches. The mathematics syllabus highlighted the importance of making connections between geometry and learners' lives and culture. The syllabus framework puts more emphasis on the use of indigenous language which concurs with the provisions of the Zimbabwe Constitution (ZIMSEC, 2015). In addition, focus of teaching geometry is to enable learners to address real-life problems through knowledge construction and not by being information receivers or empty vessels. The syllabus characterises teachers as facilitators and coaches who use learner-centred approaches in the teaching of geometry (ZIMSEC, 2015). Ethnomathematics approaches are leaner-centred approaches in the sense that they are activity-oriented and focus on the mastery of geometry content through the use of real-life examples that the learners are familiar with and related teaching resources.

Researchers such as D'Ambrosio (2001), Adam (2004), Achor, Imoko and Uloko (2009), Zhang and Zhang (2010), Rosa and Orey (2010) and Gerdes (2011) have noted numerous benefits of ethnomathematics approaches in mathematics education. For instance, integrating ethnomathematics approaches into the teaching of geometry simplifies learning, improves learners' retention and achievement, makes it more relevant and significant for learners, and promotes the total quality of geometry teaching and learning (Madusise, 2015; Rosa \& Orey, 2010).

Achor et al (2009) conducted a research in Nigeria to determine the effectiveness of ethnomathematics approaches on learners' retention and achievement on the concept of locus in geometry. The experimental and control groups of the learners were drawn from four schools. The control group was taught using the conventional approach while the experimental group was taught using an ethnomathematics approach. Learners from the experimental group were involved in mock practical work, pegging farming land as well as in thatching round huts. These activities were common cultural practices in their societies. The two groups wrote the same pre and post-tests on locus.

Findings revealed that learners who were taught using ethnomathematics approaches had higher retention as well as higher mean achievement scores than those who were taught using the conventional approach. Findings further revealed that ethnomathematics approach proved to be a viable approach in promoting meaningful learning in locus. The researchers claimed that the major reason for such findings could be that learners taught with ethnomathematics approaches were able to connect the cultural practices in their societies with the learning of locus. This implies that ethnomathematics approaches might help in reducing the abstract nature of the teaching and learning of geometry. 
Despite the contributions that integrating ethnomathematics approaches make in improving the teaching and learning of geometry as well as teacher efficiency, studies have revealed that ethnomathematics approaches were rarely used in the classroom (Madudise, 2015; Mogari, 2014; Mosimege, 2012). Researchers observed that teachers had limited knowledge on ethnomathematics approaches as well as on geometry/mathematics content knowledge which impede the integration of ethnomathematics approaches into the teaching of geometry in particular. In addition, research has indicated that even though teachers may have a conceptual understanding of ethnomathematics approaches, they do not practice them in their own classrooms (Mogari, 2014; Nawesab, 2012). Teachers argued that integration of ethnomathematics approaches into the teaching of mathematics is time consuming in terms of lesson planning and delivery (Nawesab, 2012). Furthermore, those teachers were not willing to change their traditional approaches of teaching because they do not want to change their roles of being authoritative and experts who impart knowledge to learners. It is against this background that this study intends to explore teacher-related challenges affecting the integration of ethnomathematics approaches into the teaching of geometry.

The following research question was addressed in this study to determine the challenges that teachers face when integrating ethnomathematics approaches into the teaching of geometry to improve its teaching in Zimbabwe:

What do teachers view as challenges to the integration of ethnomathematics approaches into the teaching of geometry?

\section{LITERATURE REVIEW}

\section{Social Constructivist Theoretical Framework}

The study is underpinned by the social constructivist theoretical framework (Vygotsky, 1978). Ethnomathematics approaches fit well within the social constructivist theory of having learners construct understanding and knowledge through what they have previously learned and been exposed to before (Brandt \& Chernoff, 2015). Ethnomathematics approaches subscribe to the social constructivist view that emphasises a situated and contextualised teaching and learning process (Ferner, 2013). In a geometry classroom guided by social constructivism, learners are encouraged to solve problems that resemble those in the real-life situations. Instead of solving geometry problems that are out of context, learners are challenged with contextualised problems. These enable them to link previous geometrical knowledge with new knowledge and also to transfer the new knowledge and their understandings to real-life situations.

Vygotsky's (1978) social constructivist theory is connected to ethnomathematics approaches, which puts more emphasis on the role played by culture and the environment in learners' development and learning of geometry and the importance of the learners' interaction with social beliefs and features in learning geometry. Consistent with social constructivist theory, learners first obtain cultural geometry concepts from their environment, which in reality mediates the learners' social beliefs and notions, and continue to attain and solidify their acquired knowledge in schools. Ethnomathematics approaches are grounded in the social situation of the learner; therefore, they are based on the life experience of the learner and rely on the theory of social constructivism (Ferner, 2013).

Ethnomathematics and social constructivism share common ground in two important instructive assumptions that have implications for mathematics teachers (Matang, 2009). First, learners socially construct knowledge by interacting with the environment and, second, learning occurs in realistic and contextualized daily activities that gives the appropriate background meaning to what the learners learn in the learning environment. This implies that teachers should connect their geometry teaching to the learners' experiences and environments; this view is supported by both ethnomathematicians and social constructivists. Researchers grounded their investigation on Zimbabwean in-service mathematics teachers' challenges related to the integration of ethnomathematics approaches into the teaching of geometry in the social constructivism theory.

\section{Definition and Nature of Ethnomathematics Approaches}

D'Ambrosio (2001) defined ethnomathematics approaches as techniques that build on the learners' prior understanding, experience, the role played by their environment in terms of content, approaches, and their past as well as present understanding of their immediate surroundings. Ethnomathematics approaches focus on using previously prevailing geometry experiences in the learners' surroundings, society, background as well as activities to enable them to enhance their understanding of geometry and other areas of mathematics. According to Mogari (2014), ethnomathematics approaches are learner centred and activity oriented. These approaches are embedded in social constructivism because they recognize the everyday knowledge that learners bring into the classroom (Laridon, Mosimege \& Mogari, 2005). 


\section{Integration of ethnomathematics approaches in geometry teaching}

Pinxten and François (2007) carried out a study named "Ethnomathematics in practice" that offered a few propositions about the real-world application of ethnomathematics approaches in the geometry teaching and learning environment. They embarked on a field study amongst the Navajo Indians (in the U.S.) and made use of the hooghan (traditional housing) project, which they refer to as the Navajo geometry teaching. The study involved learners who were visiting the hooghan, living in the hooghan or receiving clear descriptions about the hooghan. In the geometry classroom, learners were requested to build a hooghan which is a cosmological scale model of the world and demonstrate the Navajo concepts for above or below, proportions, shapes, symmetry, reflection, wind bearings, space to move, and so forth.

Amid this collaboration, learners rationally investigated all parts of the hooghan, similar to ideas of orientation and proportion, how a scale model is constructed and graphic presentations of the hooghan. In these exercises, Navajo dialect was utilised. After this investigation, researchers found it beneficial for learners to begin with what they were familiar with from their cultural backgrounds, envisioning the features in it and concluding with graphical illustrations to gain the intuition required to grasp the implicit view of geometry. Learners' construction of the hooghan heightened their confidence. In so doing, learners felt that the geometry they learn in the classroom also comes from their lives and cultures. This study supports Matang's (2009) view that teaching and learning of school geometry is more effective and meaningful if it is linked to familiar geometrical practices found in the learner's own cultural environment as well as using a language that learners are familiar with because knowledge is rooted in their languages.

The study cited above highlights how ethnomathematics approaches could be integrated into the teaching of geometry and some potential benefits expected after its integration. However, there are various teacher-related challenges associated with the notion of incorporating ethnomathematics approaches into the teaching and learning of geometry.

\section{Factors that affect Integration of Ethnomathematics Approaches into the Teaching of Geometry}

Teacher-related challenges have been shown to have a major influence on change and are normally deeply embedded in teachers' fundamental views, hence are the most important and resilient to change (Fullan, 2007). The views held by the teachers can either speed up or retard curriculum changes, as teachers' opinions are resilient to change and play significant roles in how teachers teach geometry (Boaler, 2013). Teachers' views about use of ethnomathematics approaches in geometry teaching and learning are influenced by factors such as teachers' views about geometry learning. Findings from a study done in Israel, Katsap and Silverman (2008) showed that teachers viewed geometry as an abstract topic. In addition, Rosa (2013) found that in California, teachers held negative beliefs about using ethnomathematics approaches; for instance, teachers in this study believed that the cultural background of learners does not influence their academic performance.

Teachers in Mosimege's (2012) study in South Africa rarely recognized the interconnection between mathematics and culture in their teaching. Teachers had superficial indigenous content knowledge, hence, their inability to make links in their mathematics classrooms (Madusise, 2015). Venkat, Bowie and Graven (2009) reported on some experimental research in mathematics classrooms in which teachers who were trying to incorporate contextualized mathematics teaching showed a lack of skills that resulted in loss of focus on mathematical aspects. Similarly, Naresh (2015) indicated that limitations in teachers' ethnomathematical knowledge and lack of training make them lack confidence in using the approaches in the teaching.

According to Madusise (2015), successful integration of ethnomathematics approaches requires sufficient and appropriate mathematical/geometrical content knowledge; inadequate mathematical/geometrical content knowledge constraints the supple and intricate use of school mathematics to read and comprehend cultural activities. Teachers' own geometry content knowledge also hinders the integration of ethnomathematics approaches in the classroom. Telima (2011) reported that most mathematics teachers' foundation in geometry was poor. This coincides with Ponte and Chapman (2006), who reviewed several studies that consistently showed that geometrical knowledge is typically challenging when it comes to how the teachers view geometry knowledge and what they know.

Their summary showed that teachers tend to lack the aptitude to link geometry to real-life situations; have difficulty processing geometry knowledge; and do not have elementary geometry knowledge, expertise and logical thinking skill. Teachers should have adequate geometrical knowledge to identify exciting, relevant geometrical problems and be able to assess various methods to solve geometry problems that learners present (Wilding-Martin, 2009). The implication is that, if a teacher does not have either the requisite knowledge or instructional understanding of geometry teaching, using ethnomathematics approaches can easily lead to disorder. 


\section{METHODOLOGY}

The present study was carried out in the Faculty of Science Education, Department of Science and Mathematics Education at a university in Zimbabwe. Even though the university was conveniently sampled, an additional essential reason behind the selection of the university was that, it is the one with the mandate of training science and mathematics teachers in Zimbabwe. The university offers a wide range of programs for in-service teachers from honours degree level up to doctoral level, as well as programs for pre-service teachers. For that reason, researchers presumed that the in-service teachers who took part in the study had experience in teaching geometry and could provide valuable information concerning teacher-related challenges on integration of ethnomathematics approaches.

\section{Participants}

The population of the research study was 80 in-service mathematics teachers (50 males and 30 females). The 40 in-service mathematics teachers (25 males and 15 females) who were enrolled in the Bachelor of Mathematics Honours degree at a university comprised the sample for both the quantitative and the qualitative phases. Proportional stratified random sampling was employed for the quantitative phase to guarantee the in-service mathematics teachers' proportional representation in the sample. In this study, gender was the stratification variable, in-service teachers were divided into two groups; one for the females and another one for the males. Two random samples were drawn separately from each group (female and male) in proportion to the gender balance in the population (Curtis \& Curtis, 2011) using simple random sampling technique. The combined random samples of male and female teachers altogether made up the sample (40 teachers) of this study.

Research-based recruitment was employed, whereby participants for the focus-group discussions were the same participants (40 teachers) who completed the questionnaires (Hennink, 2014). The 40 teachers who were recruited to complete the questionnaires through proportional stratified random sampling techniques were also randomly selected to participate in qualitative focus-group discussions. Five groups, each consisting of three female and five male in-service teachers were involved in the discussions. Even though teachers were selected through proportional stratified random sampling and research-based recruitment, their partaking in this study was voluntary.

All the teachers were Diploma holders and were teaching mathematics at secondary school level in Zimbabwe. Pertaining to the teaching profession, $(37.5 \%, \mathrm{n}=15)$, had 2-5 years teaching experience, $(50 \%, \mathrm{n}=20)$ had $6-10$ years of teaching experience, and $12.5 \%(n=5)$ had between $11-15$ years of teaching experience. Teachers are only enrolled for the in-service program if they had two years of experience teaching mathematics in secondary schools.

\section{Design}

A convergent mixed-method research approach was used in which both qualitative and quantitative data were collected in order to find an in-depth understanding of the research problem as well as counteract the weaknesses that could arise from using either method by itself. The main objective of using a combination of methods in this study was triangulation (Gray, 2011). In this convergent parallel mixed methods study, both qualitative and quantitative data were gathered simultaneously and then merged in the analysis and in the interpretation phases (Creswell \& Plano Clark, 2011).

\section{Instruments}

Data was collected using a questionnaire and focus-group discussions. These instruments were developed by the authors based on the literature (articles, theses, scientific research, and so forth). For instance, Ernest (1991) argued that teachers' opinion concerning the nature of mathematics impact their decision on teaching approaches and how they approach mathematics in the classroom. The reviewed literature of this nature helped in developing items for both the questionnaire and focus group discussions.

Questionnaires generated both quantitative and qualitative data (McMillan \& Schumacher, 2010), which is one of the major elements of this convergent parallel mixed-methods research and enables data triangulation. The questionnaire consisted of closed items and open-ended questions to allow the teachers to express their views and to find in-depth information about the challenges of integrating ethnomathematics approaches into the teaching of geometry. Questionnaires were used because they were capable of providing information about views and opinions about teacher factors that hinder the integration of ethnomathematics approaches into the teaching geometry (Gray, 2011). However, the use the questionnaires alone restricts their ability to provide in-depth clarifications from precoded answers, hence, qualitative data collection instrument such as focus group discussions were also used. Data from the focus group discussions complemented the quantitative data from questionnaires by providing additional 
Table 1. Teachers' lack of geometry knowledge $(n=40)$

\section{Representative quote}

I lacked the key needs required to teach geometry.

Not enough knowledge was acquired during my Ordinary Level.

Less knowledge on teaching geometry

Lack understanding of geometry concepts

It is not possible because some of the concepts were not even taught, for instance, transformation.

comprehensive information on teachers' challenges in integrating ethnomathematics approaches into the teaching of geometry.

\section{Procedure}

Permission to carry out the study was granted by the university as per its research policy requirement. Questionnaires were self-administered to each in-service teacher in a lecture room, which enabled high return rate, shorter data gathering period and a chance for the authors to orally explain the objective of the study as well as providing answers to questions from the participants (Gray, 2011). Following Curtis and Curtis's (2011) recommendations on ethical considerations, a letter of informed consent, was signed by the participants before they completed the questionnaire. A box near the exit to the room for collecting questionnaires helped to assure confidentiality and to maximise the response rate (Gray, 2011).

Immediately after the administering the questionnaire, focus-group discussions were conducted in which all those who were involved discussed the same questions. The focus-group discussion items and questionnaire items were content-validated by three experts with mathematics education backgrounds. The validity and reliability were attained mainly through methodological triangulation that used different data gathering methods on the same research question. The use of open-ended questionnaire question and focus group discussions, in this study, enhanced the reliability and validity of the findings.

\section{Data Analysis}

Data collected from the audio-recorded focus group discussions were transcribed by the researchers. An 'inductive' (Creswell, 2015) data analysis procedure, which involved code creation by the authors through direct interaction with the data, was used for qualitative data from both the open-ended questionnaire questions and focus-group discussions. Inductive data analysis is a procedure that involves the identification of patterns and themes in the data (Curtis \& Curtis, 2011). Grounded theory is a major tool of inductive analysis. Grounded theory puts more emphasis on generation of categories grounded in the data. In this study, the coded focus group transcripts and data from open-ended questionnaire questions was analysed using grounded theory. This study incorporated numerous strategies so that the principles of trustworthiness were achieved. In this study, trustworthiness of data collection was enhanced through mechanical means of recording focus group discussions so that they were replayed during data analysis. In addition, member checking was done to obtain accurate and complete record of results and describing how the data was collected and analysed which also enhanced the trustworthiness of the research findings. Interpretive data analysis providing meanings that go beyond straightforward depiction of the numerical data was used for the quantitative data.

\section{RESEARCH FINDINGS}

The 40 participants who completed the questionnaire also formed the five groups for the focus-group discussions and had a minimum of two years teaching experience. Research findings presented below emerged from the analysis of two data sources: questionnaires and transcripts of focus-group discussions. Findings provide the answers to the research question: What do teachers view as challenges to the integration of ethno mathematics approaches into the teaching of geometry?

\section{Inadequate Teacher Training in geometry}

Data from open-ended questionnaire questions showed that $47.5 \%$ of the teachers were not adequately prepared to teach geometry, hence their geometry content knowledge for teaching is inadequate. This is evidenced in Table 1.

The extract from the focus-group discussions supported the teachers' lack of geometry knowledge. Teachers commented:

Our geometry content mastery is low. We do not have the content required to teach geometry (Groups E and D). 
Table 2. Terminology/language of geometry $(n=40)$

\section{Representative quote}

Words and terms used were too abstract, for example, 'corresponding'/'alternate'; I do not understand what they mean.

I could not understand the concept of equidistance of shapes in geometry construction.

Too abstract

Table 3. Teachers' lack of knowledge of the interdisciplinary nature of geometry $(n=40)$

\section{Representative quote}

Lack of background knowledge.

Inability to link geometry content with other areas of mathematics, for instance matrices and vectors.

This finding concurs with Mashingaidze (2012) who pointed out that teachers have limited geometry content knowledge. Lack of knowledge is a barrier to the integration of ethnomathematics approaches into the teaching of geometry as observed by Madusise (2015). If teachers themselves have difficulties in mastering geometry content, then, communicating it to their learners will also be a problem.

Data from open-ended questionnaire questions showed that some teachers (see Table 2) stated that they had difficulties in understanding geometry, and their reasons for facing difficulties were categorised as terminology/language of geometry and teachers' lack of knowledge of the interdisciplinary nature of geometry.

\section{Terminology/Language of Geometry}

The terminology/language of geometry makes the topic difficult to some of the teachers (Table 2). This finding is in line with Cangelosi (1996) who observed that the language of geometry pose many challenges to both the learners and teachers. Researchers argue that an understanding of the language of geometry is necessary for the use of ethnomathematics approaches in its teaching.

\section{Teachers' Lack of Knowledge on the Interdisciplinary Nature of Geometry}

Geometry concepts are interrelated with many topics in mathematics. The extracts from the open-ended questions showed that teachers lacked the background knowledge that is required before they could teach geometry concepts (Table 3 ).

Data from focus-group discussions also confirmed teachers' lack of pre-requisite knowledge in geometry such as in the context of vectors and matrices, as the following teachers' extract shows:

Geometry transformation, shear, stretch and enlargement require the knowledge of vectors and matrices. It is difficult to link these geometry concepts with other topics such as matrices and vectors because we lack the knowledge on how to link these topics. We have limited prior knowledge on linking geometry concepts with topics such as vectors and matrices (Group D).

Teachers' lack of geometry pre-requisite knowledge and its interdisciplinary nature has been noted earlier by various researchers, for instance, Telima (2011); and has in this study confirmed by the participating teachers. The inadequate teachers' geometry content knowledge is also a major barrier in the incorporation of ethnomathematics approaches into the teaching and learning of geometry (Madusise, 2015).

In addition, data from the focus-group discussions revealed that teachers had some problematic areas in geometry. The following extracts are exemplars:

Yes. Transformation, shear, stretch, need of practical approach, difficult and boring tasks in these concepts, we lack knowledge on these concepts (Group E).

Yes. Transformation, circle geometry. These were skipped by teachers at secondary school.

There are too many theorems in geometry (Group D).

Teachers attributed the difficulty of these concepts to lack of knowledge, the concepts being skipped by their teachers at secondary school, too many theorems; difficult and boring tasks in these concepts. Findings concur with Mashingaidze (2012) who pointed out that geometry as a standalone topic is difficult for both teachers and the learners and it is widely skipped in the syllabus. We argue that teachers teach in the same manner that they were taught, hence, geometry concepts are likely not to be taught in the classroom. This might imply non-use of ethnomathematics approaches in the teaching of geometry. 
Table 4. Teachers' Lack of Training in Ethnomathematics $(n=40)$

\section{Representative quote}

Lecturers did not link concept to culture.

Concepts were from the syllabus only.

I still face challenges to deliver since I was taught using a demonstration method.

Table 5. Lack of knowledge on ethnomathematics approaches $(n=40)$

\section{Representative quote}

Lack of skills and knowledge by the teachers on these approaches

I do not have enough knowledge on ethnomathematics.

Inadequate knowledge to integrate culture when teaching

I was not taught to link culture in the teaching of geometry.

I lack background knowledge on such approaches.

Not equipped to teach in that method

Not really, I do not fully understanding it.

I am not aware of the methods.

Findings from the focus-group discussions showed that teachers did not feel competent to teach geometry because they felt they lacked geometry knowledge, they were not confident and geometry concepts were not fully taught during teacher training. The groups' responses were:

No, not competent at all. Not confident, we lack knowledge on geometry (Group D).

Not competent, we were not adequately taught geometry concepts, we lack knowledge to teach geometry, it was partially taught in schools (Group E).

Teachers' poor foundation of geometry was also observed by Telima (2011). Lack of geometry content knowledge hinders integration of ethnomathematics approaches into the teaching of geometry as observed by Madusise (2015). Lack of geometry content knowledge and confidence to teach it is a critical issue, because teachers' lack of geometry teaching competency increases the likelihood that because it will not be taught as planned, the integration of ethnomathematics approaches cannot be realised.

\section{Teachers were not Trained to Integrate Ethnomathematics Approaches in Teaching Geometry}

Qualitative findings from the open-ended questionnaire questions revealed that teachers (62.5\%) lacked adequate training to integrate ethnomathematics approaches in the teaching of geometry as shown in Table 4.

Teachers reported that they were not taught ethnomathematics approaches while training as teachers in teacher training institutions (Table 4). As a result, they may not make use of ethnomathematics teaching approaches when teaching geometry. The following response exemplified the lack of knowledge on how to integrate ethnomathematics approaches:

Never trained using these methods so can't use them (Group D).

Lack background knowledge on how to do it we were never given training (Group E).

Teachers have not been offered support in the form of training in ethnomathematics approaches. Findings concur with Naresh (2015) who observed that there were no ethnomathematics courses in most teachers training institutions. Researchers argue that teachers are likely to teach using teaching approaches that they are familiar with or that they experienced during their training.

Quantitative data showed that $47.5 \%$ of participants agreed that they lacked knowledge on ethnomathematics approaches. Data from open-ended questionnaire questions showed that teachers do not have adequate knowledge on ethnomathematics approaches, as shown in Table 5.

The same sentiments were echoed by the teachers in focus-group discussions. This is what they said:

We lack knowledge on how to integrate ethnomathematics approaches into the teaching of geometry (Group A).

We were never trained using such approaches so we cannot use them (Group D). 
Table 6. Lack of knowledge on cultural/contextual examples $(n=40)$

\section{Representative quote}

I do not know valid examples.

Lack of knowledge on cultural examples to use when teaching geometry

Lack knowledge on teaching methods suitable for teaching geometry incorporating culture and environment

I lack the knowledge of linking geometry to culture, the idea was not emphasized in colleges.

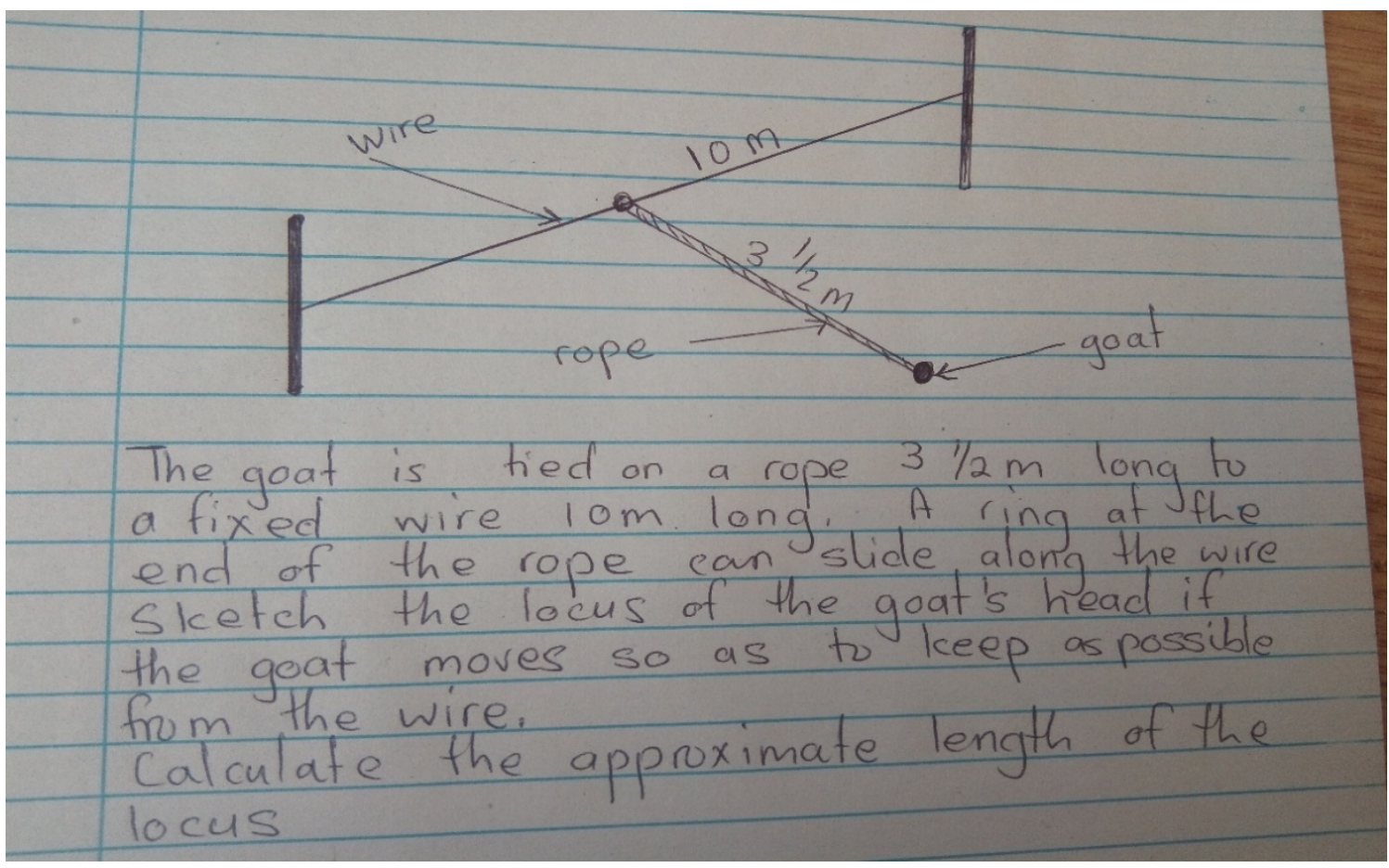

Figure 1. Group D's response

We lack the background knowledge on how to do it because we were never trained (Group E).

Teachers' lack of knowledge on ethnomathematics approaches could be one of the contributing challenges to the integration of ethnomathematics approaches into the teaching of geometry. Findings on teachers' lack of knowledge on ethnomathematics approaches is in line with Madusise (2015) who reported the teachers' inability to use ethnomathematics approaches due to lack of knowledge on ethnomathematics approaches and its application in the classroom.

Quantitative data showed that $30 \%$ of the teachers at least agreed that they could not develop culturally contextualized examples for effective geometry teaching. The data from the open-ended questionnaire questions showed that some teachers lacked knowledge on cultural/contextual examples. This is evidenced in Table 6.

Some teachers indicated that lack of knowledge on cultural/contextual examples prevented teachers from including them when planning to teach geometry (Table 6). The finding is in line with Madusise (2015) who observed that teachers' ethnomathematical knowledge was limited. Before ethnomathematics approaches can be integrated into the teaching of geometry, teachers should develop an understanding, expertise and knowledge required for such an approach. With such limited ethnomathematical knowledge teachers would not be in apposition to use ethnomathematics approaches in the teaching of geometry.

In addition, teachers indicated that their lecturers used geometry cultural examples that they were not familiar with. This is what the teachers from Group D said:

For instance, the question in Figure 1 showing a goat tied on a rope, was meaningless to us because we did not know anything about the goats (Group D).

The example was relevant to teachers that were aware of the goats, hence, it did not cater for all the teachers due to cultural diversity. Therefore, it is important for lecturers to be knowledgeable about their own culture and 
Table 7. Resistance to change by teachers $(n=40)$

\title{
Representative quote
}

Reluctance to conform to new changes.

Resistance from the teachers.

The teachers might take it for granted.

how cultural preconceived notion might influence teaching strategies, which in turn influence their learners' understanding and performance in geometry (Rosa, 2006).

\section{Teachers' Views on Geometry Content Taught in Schools}

Teachers indicated that content of geometry taught in schools is not sensitive to culture because of the foreign examples and the language used in textbooks and due to the nature of geometry. The following excerpts were fairly common among the participants who said school geometry is not sensitive to cultural interest:

\begin{abstract}
Insensitive and discriminative to cultural examples, examples from foreign countries are normally used in textbooks. Even the language used in text books is discriminative, though the new curriculum encourages the use of the learners' first language, the textbooks still do not have such examples and from the requirements of the new curriculum it seems it is still examination bound (Group A).
\end{abstract}

Geometry taught in schools is not sensitive to culture (Group B).

It is discriminative of cultural interests. (Group E).

Furthermore, teachers from Group B said:

Shapes in geometry are perfect arts and lines and natural shapes are not perfect, at times fail to match with the curriculum shapes. Geometry concepts taught in schools are prescribed from regular, geometry from culture is not regular, and, for example, the circles from the round huts and kraals are irregular (Group B).

These views tend to make the teachers resort to teacher-centred approaches to geometry teaching. This finding concurs with Ernest's (1991) traditionalist view of mathematics where mathematics is taught as a discipline that is not sensitive to culture. Such views promote the use of teacher-centred approaches and activities in the teaching of geometry, hence, ethnomathematics approaches would never be realised in such geometry classrooms.

\section{Teachers' Views on Their Roles for Teaching Geometry}

Teachers' views of their roles in the classroom affect the integration of ethnomathematics approaches into the teaching of geometry. Teachers who perceive their role as being a lecturer are likely not to integrate ethnomathematics approaches into the teaching of geometry. The following example from the focus-group discussions is an expression of this role:

We bring all the learners to the practical part of geometry in shapes. To bring the right terminology as prescribed in the curriculum (Group B).

The views held by the teachers about their roles in geometry teaching influences how geometry is taught in the classroom. Teachers' views about their roles tend to contradict what is prescribed by ZIMSEC (2015) in the syllabus, where they are supposed to be facilitators and coaches of the teaching-learning process.

\section{Resistance to Change by Teachers}

Teachers find it challenging to change their role from being a teacher to being a facilitator of learning. The integration of ethnomathematics approaches in teaching geometry requires changes in the skills, practices and views of the teachers and how the teachers perceive their learning environments. The approaches to teaching geometry have to change from traditional teaching approaches to ethnomathematics approaches. Teachers are also expected to change from their role as a content expert to a facilitator, which might lead to some teacher resistance. Teachers' extracts from the questionnaire given in Table 7 provide evidence. 
Data from the open-ended questionnaire questions corroborate the data from the focus-group discussions, where the teachers mentioned they were resistant to change. The following examples from group-discussion data show the teachers' expressions of their concerns:

We are to change from being teacher centred to learner centred that requires us to become facilitators. It is better to do what we are used to (Group C).

Teachers are resistant to change because they are colonized by the current use of technology (Group E).

In order for the teachers to change from their use teacher-centred approaches to a more learner-centred approach of learning, there is a need for radical shift in their roles as teachers. This requires that a teacher is no longer a provider of geometry knowledge content, but rather facilitates the teaching and learning process.

\section{DISCUSSION}

This section discuses teacher-related challenges on integrating ethnomathematics approaches into the teaching of geometry.

\section{Inadequate Teacher Training in Geometry}

Effective teaching may not be realised without adequate geometry-related knowledge for teaching. Lack of geometrical content knowledge may indicate that teachers are not capable of teaching geometry, therefore, making it difficult for them to integrate ethnomathematics approaches into a topic that the teachers themselves do not understand. Findings of this study are similar to those of Ponte and Chapman (2006), who reported that teachers do not have basic geometrical knowledge and skills for teaching it. In an ethnomathematics classroom, teachers must possess geometry content knowledge because they are tasked with the responsibility of choosing cases that are related to the learners' cultural background and environment (Rosa \& Orey, 2006).

The terminology/language of geometry has been indicated as one of the reasons for facing difficulties in understanding geometry concepts. Bishop (1986) also reported that many geometry learners have weaknesses in their geometry vocabulary. Misuse of geometrical terms can also lead to misunderstandings of geometric concepts (Bishop, 1983).

The teachers indicated that they lacked background knowledge on geometry. This finding is in line with Noraini (2006) and Telima (2011), who reported that one of the factors that are responsible for the difficulty in understanding geometry is a lack of background knowledge. In addition, the teachers reported their inability to relate geometry to the other mathematics topics. The lack of background knowledge and the inability to connect geometry to the other mathematics topics hinders the integration of ethnomathematics approaches into the teaching of geometry.

Teachers cannot be effective in the teaching of geometry if they have some inadequacies. They cannot teach well what they do not know very well (Mogari, 2014). Teachers who are not confident about their own ability to teach geometry will have fewer possibilities when making decisions about the teaching approaches to be used. These teachers are also not in a position to apply wide, deep and integrated sets of geometry knowledge and skills in the classroom. Feelings of inadequacy in teaching geometry can affect the integration of ethnomathematics approaches and may result in overreliance on textbooks or avoidance of geometry topics. Teachers need a deep understanding of all aspects of geometry so that they can present and explain geometry concepts and show how they relate to other mathematics topics. Geometry is one of the topics that is covered in the mathematics syllabus yet teachers are not well equipped to teach such a topic. This shows a disjunction between what the teachers are capable of teaching and the requirements of the syllabus.

\section{Teachers were not Trained to Integrate Ethnomathematics Approaches in Teaching Geometry}

Findings of the study indicate that many teachers $(62.5 \%)$ in the field did not receive enough professional training and orientation with regard to ethnomathematics approaches. This lack of training may lead to a lack of integration of ethnomathematics approaches into the teaching of geometry due to inadequate knowledge and skills. Teachers' lack of training on the integration of ethnomathematics approaches into the teaching of geometry helps in explaining why they are typically reluctant to try this instructional approach (Rosa \& Orey, 2013; Velasquez, 2014). Having the knowledge of how to integrate ethnomathematics approaches in teaching is essential for its adequate integration into the teaching geometry. Teachers need to give all the learners a chance to learn according to their needs, cultural understandings and practices, which requires them to have the knowledge to do so. 
Some of the teachers felt that the teaching methods employed by their lecturers did not sufficiently link geometry teaching and learning to cultural examples and experiences. Over-reliance on the syllabus was also an element of the lecturers' practices. This finding corroborates earlier findings by Rosa and Orey (2006) in a study that found that educators were not allowed to teach what was not stipulated in the syllabus. Teachers' professional experience participating in professional learning environments in which ethnomathematics approaches were not integrated affects their use of ethnomathematics approaches. Teachers who have more teaching and professional experience with the traditional methods of teaching as learners or teachers are likely not to integrate ethnomathematics approaches into the teaching of geometry.

According to Rosa (2013), a deep understanding of both culture and its association with geometry is an essential source of knowledge for teachers in order for them to integrate ethnomathematics approaches when teaching. Teachers' lack of knowledge of cultural examples was mentioned as one of the contributing challenges to the integration of ethnomathematics approaches into the teaching of geometry. This finding is in line with Mosimege (2012), who found that teachers lacked the ability to make connections in their teaching. In addition, in Mogari's (2014) study, teachers were not able to develop and use their own ethnomathematical activities. Teachers are often unaware of the association between mathematics and culture due to the lack of culture in content and instructional approaches in these traditional learning environments (Bishop, 2002; D'Ambrosio, 2001). Teacher's knowledge about cultural/contextual examples influences the possibility of using ethnomathematics approaches in geometry teaching.

Findings of the study revealed that teachers were not trained to integrate ethnomathematics approaches into the teaching of geometry and they also lacked knowledge on cultural examples. These findings are not in line with the requirements of the syllabus, implying that there are gaps between the teacher training institutions and expectations of the syllabus. In other words, teachers might not meet the demands of the syllabus.

\section{Teachers' Views on Geometry Content Taught in Schools}

Teachers indicated that the content of geometry taught in schools was not sensitive to local culture because of the foreign examples and language used in textbooks and due to the nature of geometry itself. Teachers' views indicate that geometry taught at schools does not accommodate the cultural interests of the several indigenous groups in the Zimbabwe. The traditionalist stance claims that geometrical knowledge is value free and is free from culture (Ernest, 1991). The view that geometry is culture free is part of the long-reported view that mathematics in general, including geometry, is neutral and culture free (Bishop, 2004; D'Ambrosio 2001; Enerst, 1991; Matang, 2009). This view has subjugated modern geometry classroom practices, which disrespect the rich real-life out-ofschool geometry that learners take along into the teaching and learning environment. The view that the geometry being taught in schools in insensitive to culture may contribute to its lack of relevance to learners' everyday life and culture. The traditional view of geometry favours a teaching and learning process that is disconnected to the learners' experiences, culture and knowledge. As a result, teachers may not see the association between geometry and culture, yet it is a requirement of the syllabus to relate geometry teaching to the learners' cultural background and environment.

Although, the Zimbabwean mathematics curriculum supports the use of the learners' own language, the textbooks and the examinations still use the English language that is foreign to both teachers and learners. This is an example where the curriculum contradicts itself in terms of its objective on the use of the local/indigenous language yet all the final formative and summative examinations are written in English a second language to Zimbabwean learners. In addition, the textbooks do not have local cultural examples but rather examples from foreign countries. This finding coincides with earlier findings from Sibanda, Mtetwa and Zobolo (2007). The use of foreign examples may make it harder for teachers to explain geometrical examples that are foreign to both teachers and learners.

In addition, the curriculum being examination bound and content focused may have implications on teachers' selection of the teaching approaches. Examination-bound curriculums are based on what Ernest (2009) referred to as the traditionalist views of mathematics, where teacher-centred approaches are used to speed up the coverage of the all the curriculum topics in preparation for examinations.

\section{Teachers' Views on Their Roles for Teaching Geometry}

It is possible that the role mentioned by these teachers relates to their views about the teaching and learning of geometry. Ernest (1988) linked teachers' views of mathematics with their conceptions of teachers' roles and the teaching of mathematics. Ernest (1988) further said that teachers' own conceptions of their roles and conceptions of the purpose of teaching affect their instructional and curricular decision-making. In this study, teachers' role of imparting knowledge is grounded in Ernest's (2009) traditional view of mathematics that are teacher centred. The 
view held by the participating teachers on their roles of teaching geometry contradicts the roles of teachers as facilitators and coaches prescribed in the syllabus by ZIMSEC (2015).

\section{Resistance to Change by Teachers}

The resistance of the teachers may indicate their satisfaction with traditional teaching methods and their lack of readiness for change. Ethnomathematics approaches have implications for the roles of both teachers and learners. Teacher's role is that of a facilitator when using ethnomathematics approaches or in a learner centred environment as prescribed by ZIMSEC (2015), while that of the learner is to actively construct their own knowledge. In practice, ethnomathematics approaches require the teacher to acknowledge learners as equal partners in the teaching and learning process, inspiring them to contribute meaningfully to geometrical activities, hence, teachers tend to resist due to the changes in roles.

\section{CONCLUSION}

The aim of this study was to examine teacher-related challenges in integrating ethnomathematics approaches into the teaching of geometry. Findings of this study show that the main challenges were lack of geometry content knowledge, lack of understanding of ethnomathematics approaches, and lack competence and confidence in teaching geometry. Since geometry content knowledge and conceptual understanding of ethnomathematics approaches were found to be among the critical components for the integration of ethnomathematics approaches, effective professional development needs to be provided for teachers. It is recommended that the teachers be helped to develop awareness of ethnomathematics approaches. Knowledge of ethnomathematics approaches would help in making the teachers' pedagogical approaches more flexible and learner-centred.

\section{Limitation of this Study}

This study is limited in the sense that it focussed on one topic in the mathematics syllabus which was geometry. The other limitation is that the study focussed on mathematics teachers from one teacher training institution.

\section{Areas of Further Study}

Studies could be done with other topics in the syllabus as well as with all teacher training institutions in Zimbabwe.

\section{REFERENCES}

Abreu, G., Bishop, A. J., \& Presmeg. N. (2002). Transitions between Contexts for Mathematical Learning. Dordrecht: Kluwer Academic Publisher. https:/ / doi.org/10.1007/0-306-47674-6

Achor, E. E., Imoko, B. I., \& Uloko, E. S. (2009). Effects of ethnomathematics teaching approach on senior secondary students' achievement and retention in Locus. Educational Research and Review, 4(8), 385-390.

Adam, S. (2004). Ethnomathematical Ideas in the Curriculum. Mathematics Education Research Journal, 16(2), 49-68. Retrieved 30 January 2014 from http:/ / www.merga.net.au/documents/RR_adams.pdf

Barton, B. (1996). Making Sense of Ethnomathematics: Ethnomathematics Is Making Sense. Educational Studies in Mathematics, Socio-Cultural Approaches to Mathematics Teaching and Learning, 31(1/2), 201-233. https:// doi.org/10.1007/BF00143932

Bishop, A. (1983). Space and geometry. In Lesh, R. \& Landau, M (Eds.), Acquisition of mathematics concepts and processes (pp. 223-254). New York: Academic Press.

Bishop, A. (1986). "What are some obstacles to learning geometry?" Studies in mathematics education, UNESCO. 5, 141-159.

Bishop, A. J. (2002). Critical Challenges in Researching Cultural Issues in Mathematics Education. Journal of Intercultural Studies, 23(2), 119-131. https:/ / doi.org/10.1080/07256860220151041

Bishop, A. J. (2004). Mathematics Education in Its Cultural Context. In T. P. Carpenter, J. A. Dossey \& K. L. Koehler (eds.), Classics in Mathematics Education Research (pp. 200-207), National Council of Teachers of Mathematics: Reston.

Boaler, J. (2013). Experiencing School Mathematics: Traditional and Reform Approaches to Teaching and their Impact on Student Learning. Routledge. Retrieved on 3 May 2011 from http:/ / books.google.com

Brandt, A., \& Chernoff, E. J. (2015). The Importance of Ethnomathematics in the Math Class. The Ohio Journal of School Mathematics, 71(Spring), 31-36. 
Cangelosi, J. S. (1996). Teaching Mathematics in Secondary and Middle School: An alternative approach. New Jersey: Prentice Hill.

Chiwiye, T. (2013). Assessment of mathematics and science subjects in Zimbabwe: ZIMSEC Perspective, ZimSEC.

Creswell, J. W. (2015). A concise introduction to mixed methods research. Thousand Oaks, CA: Sage Publications.

D'Ambrosio, U. (2001). What is Ethnomathematics and how can it help children in schools? Teaching Children Mathematics, 7(6), 308-310.

Ernest, P. (1991). The Philosophy of Mathematics Education, Studies in Mathematics Education. London: Routledge Falmer.

Ernest, P. (1998). Social Constructivism as a Philosophy of Mathematics. Albany, NY: SUNY Press.

Ernest, P. (2009). New philosophy of mathematics: Implication for mathematics education. In B. Greer, S. Mukhopadhyay, A. B. Powell, \& S. Nelson-Barber (Eds.), Culturally responsive mathematics education (pp. 4364). New York, NY: Routledge.

Ferner, B. R. (2013). Elementary Teacher Candidates' Images of Mathematics, Diverse Students, and Teaching: An Exploratory Study with Implications for Culturally Responsive Mathematics Education (EdD thesis), Portland State University.

Fullan, M. (2007). The New Meaning of Educational Change. Routledge. Retrieved on 23 June 2012 from http:/ / books.google.com

Gerdes, P. (2011). African Basketry: Interweaving Art and Mathematics in Mozambique. Bridges 2011: Mathematics, Music, Art, Architecture, Culture, 9-16.

Gray, D. E. (2011). Doing research in the real world. Thousand Oaks: SAGE Publications Inc.

Hennink, M. M. (2014). Focus group discussions. Understanding qualitative research. New York: Oxford University Press. https:// doi.org/10.1093/acprof:osobl/9780199856169.001.0001

Jones, K. (2002). Issues in the teaching and learning of geometry. In Linda Haggarty (Ed) Aspects of teaching secondary mathematics: perspectives on practice (pp. 121-139). London: Routledge Falmer. https:/ / doi.org/10.1002/tl.62

Katsap, L., \& Silverman, F, L. (2008). A case study of the role of ethnomathematics among teacher education students from highly diverse cultural backgrounds. The Journal of Mathematics and Culture, 3(1), 67-102.

Laridon, P. E. L., Mosimege, M., \& Mogari, D. (2005). Ethnomathematics in developmental curriculum research in South Africa. In C. Keitel, R. Vithal and J. Adler (Ed) Handbook of research in mathematics education in South Africa (pp. 133-160). Pretoria: HSRC Press.

Madusise, S. (2015). Cultural villages as contexts for mediating culture and mathematics education in the South African curriculum. Revista Latinoamericana de Etnomatemática, 8(2), 11-31.

Mashingaidze, S. (2012). The Teaching of Geometric (Isometric) Transformations at Secondary School Level: What Approach to Use and Why? Asian Social Science, 8(15), 197-210. https:/ / doi.org/10.5539/ass.v8n15p197

Matang, R. A. (2009). Linking Ethnomathematics, Situated cognition, Social constructivism and Mathematics education: An example from Papua New Guinea. The Glen Lean Ethnomathematics Research Centre, University of Goroka, Papua New Guinea.

Matang, R. A., \& Owens, K. (2004). Rich Transitions from indigenous counting systems to English arithmetic strategies: Implications for Mathematics Education in Papua New Guinea. Paper presented in Discussion Group 15 at the 10th International Congress on Mathematical Education. Copenhagen: Denmark.

McMillan, J. H., \& Schumacher, S. (2010). Research in Education, Evidence-based Inquiry. New Jersey: Pearson.

Mogari, D. (2014). An in-service programme for introducing an ethnomathematical approach to mathematics teachers. Africa Education Review, 11(3), 348-364. https:/ / doi.org/10.1080/18146627.2014.934992

Mosimege, M. D. (2012). Methodological challenges in doing ethnomathematical research. International Journal of African Renaissance Studies-Multi-Inter and Transdisciplinary, 7(2), 59-78. https:/ / doi.org/10.1080/18186874.2013.774698

Naresh, N. (2015). The role of a critical ethnomathematics curriculum in transforming and empowering learners. Revista Latinoamericana de Etnomatemática, 8(2), 450-471.

Naweseb, F. T. (2012). An investigation of basic education teachers' diploma (BETD) teachers' ability to use everyday contexts in the teaching of mathematics at junior secondary schools in Windhoek, Namibia. Retrieved on 15 July 2015 from http:/ / hdl.handle.net/11070/888

Noraini, I. (2006). Teaching and learning of mathematics: Making sense and developing cognitive abilities. Perak: Utusan Publication Sdn. Bhd. 
Pinxten, R., \& François, K. (2007). Ethnomathematics in Practice. In K. François \& J.P. Van Bendegem (Eds.), Philosophical Dimensions in Mathematics Education (pp 213-227). New York: Springer. https://doi.org/10.1007/978-0-387-71575-9_10

Ponte, J. P., \& Chapman, O. (2006). Mathematics teachers' knowledge and practices. In A. Gutierrez \& P. Boero (Eds), Handbook of research on the psychology of mathematics education: Past, present and future. Rotterdam: Sense.

Rosa, M. (2013). Accessing the perceptions of high school teachers about the influence of language and culture in the mathematics learning of English language learners (ELLs) students. Linguistics, Culture E Education, 2(1), 36-71.

Rosa, M., \& Orey, D. (2013). Culturally relevant pedagogy as an ethnomathematical approach. Journal of Mathematics and Culture, 7(1), 74-97.

Rosa, M., \& Orey, D. C. (2006). Current approaches in the ethnomathematics as a program: Delineating a path toward pedagogical action. BOLEMA, 16(20), 1-16.

Rosa, M., \& Orey, D. C. (2010). Culturally relevant pedagogy: ethno-mathematical approach. Horizontes, $28(1), 19$ 31

Sibanda, T., Mtetwa, D., \& Zobolo, A. (2007). Mathematical ideas in some cooperative work activities of the Shangani people of southern Zimbabwe. African Journal of indigenous Knowledge systems, 6(1), 51-56.

Sunzuma, G., Masocha, M., \& Zezekwa, N. (2012). Secondary school students' attitudes towards their learning of geometry: A survey of Bindura urban secondary schools. Greener Journal of Educational Research, 3(8), 402410. https:/ / doi.org/10.15580/GJER.2013.8.051513614

Telima, A. (2011). Problems of teaching and learning geometry in secondary schools in Rivers State, Nigeria. International Journal of Emerging Science, 1(2), 143-152.

Ukpokodu, O. N. (2011). How Do I Teach Mathematics in a Culturally Responsive Way? Identifying Empowering Teaching Practices. Multicultural Education, 18(3), 47-56.

Velasquez, R. B. (2014). Teachers' perceptions of teaching culturally-based mathematics curriculum units (Doctoral dissertation). Honolulu. University of Hawaii.

Venkat, H., Bowie, L., \& Graven, M. (2009). Positions and purposes for contextualization in Mathematics education in South Africa. African Journal of Research in mathematics, Science and Technology Education, Special Issue, 8195. https:// doi.org/10.1080/10288457.2009.10740663

Vygotsky, L. S. (1978). Mind in society: The development of higher psychological processes. Cambridge, MA: Harvard University Press.

Wilding-Martin, E. C. (2009). Paul Ernest's social constructivist philosophy of mathematics education. ProQuest, UMI Dissertation Publishing.

Zhang, W., \& Zhang, Q. (2010). Ethnomathematics and its integration within the mathematics curriculum. Journal of Mathematics Education, 3(1), 151-157.

Zimbabwe School Examination Council. (2009). 'O' Level mathematics examination report (4008/4028) for Examination in November 2012-2017. Zimbabwe: ZIMSEC, Harare.

Zimbabwe School Examination Council. (2010). 'O' Level mathematics examination report (4008/4028) for Examination in November 2012-2017. Zimbabwe: ZIMSEC, Harare.

Zimbabwe School Examination Council. (2011). 'O' Level mathematics examination report (4008/4028) for Examination in November 2012-2017. Zimbabwe: ZIMSEC, Harare.

Zimbabwe School Examination Council. (2015). 'O' Level mathematics examination report (4008/4028) for Examination in November 2012-2017. Zimbabwe: ZIMSEC, Harare.

Zimbabwe School Examination Council. (2015). 'O' Level Syllabus Mathematics (4008/4028) for Examination in November 2012-2017. Zimbabwe: ZIMSEC, Harare.

\section{http://www.ejmste.com}

